\title{
Tra $i$ Leoni: Revealing the Preferences Behind a Superstition
}

\author{
Giovanna M. Invernizzi* Joshua B. Miller * \\ Tommaso Coen Martin Dufwenberg \\ Luiz Edgard R. Oliveira
}

06 Mar 2019

For latest version, click here: https://osf.io/c5hxs

\begin{abstract}
We investigate a superstition for which adherence is nearly universal. Using a combination of field interventions that involve unsuspecting participants and a lab-style value elicitation, we measure the strength of peoples' underlying preferences, and to what extent their behavior is driven by social conformity rather than the superstition itself. Our findings indicate that both mechanisms influence behavior. While a substantial number of people are willing to incur a relatively high individual cost in order to adhere to the superstition, for many, adherence is contingent on the the behavior of others. Our findings suggest that it is the conforming nature of the majority that sustains the false beliefs of the minority.
\end{abstract}

JEL Classification Numbers: C93; D01; D91.

Keywords: Superstition; Conformity; Field Experiment; Lab-in-the-Field.

\footnotetext{
${ }^{*}$ Contributed equally. Invernizzi: Department of Political Science, Columbia University; gmi2105@columbia.edu. Miller: FAE, Universidad de Alicante; joshua.benjamin.miller@gmail.com. Coen: Department of Economics, Brown University; Tommaso_Coen@brown.edu. Dufwenberg: Departments of Economics, University of Arizona and University of Gothenburg, and CESifo; martind@eller.arizona.edu. Oliveira: Federal Reserve Bank of San Francisco; luiz.oliveira@sf.frb.org. This work does not necessarily reflect the views of the Federal Reserve Bank of San Francisco or the Federal Reserve System and was completed prior to Olivera's affiliation. We are grateful to Bocconi University, which provided the funding. This draft has benefitted from helpful comments and suggestions from Douglas Bernheim, Gary Charness, Filip Fidanoski, Aidin Hajikhameneh, Michael McBride, and Stuart Vyse. We would also like to thank seminar participants at University Of Southern Denmark, UC Santa Barbara, Stanford Behavioral Lunch, University of New South Wales, Renmin University, as well as conference participants at $1^{\text {st }}$ CoCoLab Workshop, University of Cte dAzur, Economic Science Association World Meeting, and the Southwest Experimental and Behavioral Economics conference (SWEBE).
} 
"Chi passa tra i Leoni,

non si laurea in Bocconi."

\section{Introduction}

Superstitions influence behavior in striking ways. Fear of the number 13 ("triskaidekaphobia") causes hotel guests to avoid the $13^{\text {th }}$ floor, and leads most US buildings over twelve floors to have the $13^{\text {th }}$ floor numbered 14 (Carroll 2007; Perkins 2002). Belief in the Chinese Zodiac influences the timing of births in many Asian families, and appears to influence parental investment as well (Goodkind 1991; Johnson and Nye 2011; Yip, Lee, and Cheung 2002). The indirect economic repercussions reach far. Having the $13^{\text {th }}$ floor labeled as the $14^{\text {th }}$ can impede the response of emergency personnel (Perkins 2002). The disproportionate number of births in dragon years causes demand spikes for limited public services (Wong and Yung 2005).

The well-documented prevalence of socially costly superstitious behavior highlights its economic relevance, and suggests an opening for policy. To this end, it is important to develop a better understanding of the nature, and strength, of people's underlying preferences, beyond the aggregate patterns that they generate.

Most common superstitions involve behavior related to the control of good or bad luck. ${ }^{1}$ Various psychological accounts for why individuals prefer to engage in superstitious behavior have been investigated (see Vyse 2013). On the other hand, prior studies have typically not investigated alternative explanations for superstitious behavior, such as the role of social preferences. ${ }^{2}$

\footnotetext{
${ }^{1}$ See for instance Kramer and Block (2008). The term "superstition" does not appear to have a commonly agreed upon definition; see Vyse (2013), Risen (2016) and Lindeman and Svedholm (2012) for different accounts and relevant discussions.

${ }^{2}$ An exception is Hajikhameneh and Iannaccone (2017), who provide evidence for how social preferences are relate to false beliefs about agency.
} 
Importantly, the strength of people's underlying preferences has generally not been measured. ${ }^{3}$

The goal of the present study is to investigate a widely-adhered to superstition and to measure the strength of the adherents' underlying preferences. Further, we explore the extent to which a preference to conform to the behavior of others may lead people to act as if they believe in the superstition, and, in turn, validate the beliefs of those who do. ${ }^{4}$

We examine a striking pattern of superstitious behavior that is widespread among students at Bocconi University in Milan, Italy. ${ }^{5}$ Using a combination of field interventions involving unsuspecting participants and a lab-style value elicitation, we reveal the preferences behind their superstition. While the object of study is idiosyncratic to Bocconi university, the hypotheses we test are of general interest and our results provide insight by analogy for completely different settings.

We next describe, in turn, the superstition, the psychological aspects of interest, and our research methods.

The Superstition "Via Sarfatti 25" is the oldest building of classrooms at Bocconi University, and most lectures are held there. The entrance is broad, with three adjacent passageways. The middle passageway is separated from the adjacent lateral ones by two columns, each of which is fronted by a statue of a lion. A widely known refrain, after which the campus newspaper "Tra i Leoni" is named, has it that "One who passes between the lions, will not graduate at Bocconi," which is a translation from the Italian original seen above. Accordingly, students almost universally shun the middle passageway,

\footnotetext{
${ }^{3}$ In contemporaneous work, Ya'akov, Ruffle, and Shtudiner (2018) find that Israeli women in the second half of pregnancy are more willing to incur a cost to avoid challenging their superstition not to decorate a room before the baby is born.

${ }^{4}$ Conformity is a topic interest among psychologists and economists, see Bernheim (1994), Bernheim and Exley (2015), Pryor, Perfors, and Howe (2018) for relevant work.

${ }^{5}$ At the time when the study was conducted, all authors were affiliated with Bocconi University, either as faculty, or students.
} 
opting instead for one of the two lateral passageways. The impact on the flow of students in and out is stark. Fewer than 1 in 20 people entering or exiting the building pass between the lions, and the ones who do are almost invariably faculty or foreign exchange students.

The Preference Why do students appear to have an aversion to walking between the lions? We consider two explanations:

1. The students prefer to adhere to the superstitious rule per se. For example, they may believe that they will not graduate if they violate it, or at least that the probability of such a bad outcome increases non-negligibly. ${ }^{6}$

2. The students prefer to conform to behavior of their peers. For example, because (virtually) all of the other students take a lateral passageway, they follow suit in order to avoid behaving differently.

Our goal is to shed light on the empirical relevance of these two explanations among the student population, and to measure the strength with which the aversion is held.

The Methods To evaluate the empirical relevance of explanations 1 and 2, while at the same time measuring the strength of students' aversion to walking between the lions, we conducted three independent but complementary experiments:

Study 1 involves a field intervention in which we block off one of the two lateral passageways, thereby increasing the cost of indulging the superstition. Our main goal is to rule out a potential confound to explanation 1 and 2 . It is conceivable that students who walk through the lateral passageways, rather than the middle, do so merely because this offers the shortest path

\footnotetext{
${ }^{6}$ We infer student beliefs from their avoidance behavior rather than eliciting their beliefs directly.
} 
to any other location on campus. If so, however, students who would have walked through the blocked-off lateral passageway had it not been blocked should now walk through the middle passageway, as it offers a shorter path to their destination.

Study 2 involves another field intervention, conducted during an evacuation drill. The evacuation drill offered an alternative approach to ruling out the shortest-path confound as the drill imposed considerable waiting cost on those exiting through the lateral passageways. Further, we sent groups of student confederates, with whom we had contracted, to walk through the middle passageway. The purpose was to reduce the cost of walking through the middle passageway for any student affected by explanation 2 . We measure the degree to which our intervention caused more students to walk through the middle. $^{7}$

Study 3, which combines lab and field features, quantifies the strength of students' aversion to walking between the lions, and uses different treatments to further evaluate relevance of explanations 1 and 2. Using a simple and novel adaptation of the Becker-DeGroot-Marschak method (Becker, Degroot, and Marschak 1964), we elicit the students willingness-to-accept money in exchange for agreeing to walk through the lions. Depending on treatment, they were informed either that they would walk "alone" or "together with the others that accept".

The remainder of the paper is organized as follows. The three studies, as well as the results we obtained, are described in depth across sections 2-4. Section 5 summarizes and concludes.

\section{Blocked Passageway - Study 1}

The fact that students are all familiar with the superstition against taking the middle passageway and behave in accordance with it, does not guarantee

\footnotetext{
${ }^{7}$ This design has similarities with Pole, Berenson, Sass, Young, and Blass (1974).
} 
that their behavior reflects an underlying aversion to the middle passageway. For example, any student who wishes to minimize the distance of the route between his or her classroom and another destination on campus should not take the middle passageway, as it is visibly obvious that taking the middle passageway will (slightly) increase the distance traveled. ${ }^{8}$ In addition, given that students do not use the middle passageway, any student without a clear preference among passageways may find following other students (herding), or repeating his or her previous decision (habit), to be less costly than deciding which passageway to take each time, anew.

Study 1 was designed to test whether the non-use of the middle passageway is driven by an underlying preference to avoid it. To this end, we design a simple field experiment in which one of the lateral passageways near the building entrance was blocked off for a period of time, and student responses were observed.

Design A 15 minute intermission period between classes was chosen to observe students entering and exiting the building. A total of 850 people were observed, and video-recorded, choosing whether to take the left, middle or right passageway as they entered (or exited) the main lecture building at Bocconi University.

The treatment intervention followed a between-subjects reversal-like (ABA) experimental design, in which the people entering and exiting the building were "assigned" to the first control group in the first 5 minutes of the observation period, the treatment group in the second 5 minutes of the observation period, and the second control group in the final 5 minutes of the observation period. 9

\footnotetext{
${ }^{8}$ The reason for this is because doors in front of each passage face the street, and the sidewalk is bordered by a hedge. For any student entering the building, the nearest door will not be the middle one. For any student exiting the building, he or she will have to make an immediate left or right turn. The Google streetview image of the building entrance (Via Sarfatti 25) can be found here: https://goo.gl/maps/xpcAPew6ry12.

${ }^{9}$ The period of observation (15 minutes) was chosen to coincide with the time between
} 
The treatment involved blocking the right passageway (as seen from the inside of the building). The obstructions used to block the passageway were not perfect and could be navigated by a determined student willing to incur some cost of delay, and effort. ${ }^{10}$

This design allows us to determine if students harbor an underlying aversion to taking the middle passageway: after abandoning the obstructed right passageway, will students reveal their aversion by choosing the further left passageway over the more convenient middle one?

Results In the time periods not including the intervention students chose the right passageway 58.5 percent of the time, the left passageway 36.7 percent of the time, and the middle passageway 4.7 percent of the time. When the right passageway is (partially) blocked students' choice of passageway revealed strong evidence of an aversion to taking the middle passageway. The students who are diverted away from the right passageway invariably choose the further left passageway over the closer middle one. Figure 1 plots for each door the percentage point change in the number of students choosing each passageway when the right passageway is blocked. As can be seen, there is no increase in the number of students passing through the middle passageway.

Discussion The patterns uncovered by Study 1 cannot be explained by students minimizing the distance traveled, or reducing the cost of choosing between subjectively equivalent passages via herding or habit. Instead, when faced with an additional cost to behaving in accordance with the superstition, students choose to incur the cost and avoid walking between the lions.

the ending and starting points of the classes in order to maximize the potential number of students observed.

${ }^{10}$ The passageway was blocked with a large tripod and camera, as well as experimenters interacting with the tripod, camera, and each other. Experimenters had large press badges hanging from their necks to induce any observer to think it was an official photography session, so as to be discouraged from interfering. 


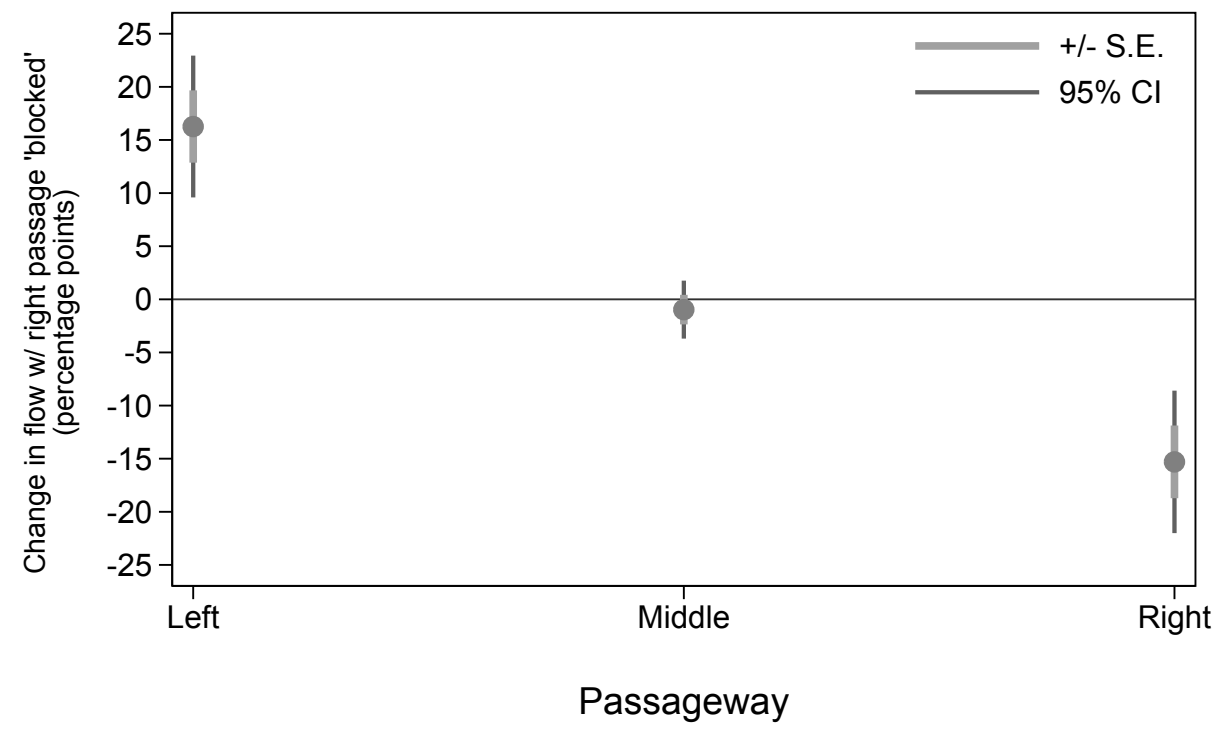

Figure 1: The marginal effect of partially blocking the right door on the percentage of students passing through each passageway (multinomial logit model). The standard errors are approximated using the Delta-method.

\section{Evacuation Drill - Study 2}

While our first study establishes that some concern for superstition affects most students, the reason why students behave as they do is less clear. As mentioned in the introduction, one potential explanation is that students are directly influenced by superstitious beliefs, i.e. they wish to avoid the potential material or emotional consequences associated with violating the rule. ${ }^{11}$ Another explanation is that students prefer to conform to existing social norms.

Study 2 is designed to test (i) whether the aversion to walking between the lions can be attributed, at least in part, to a preference to conform, and (ii)

\footnotetext{
${ }^{11}$ Material and emotional consequences are not necessarily separable. While some students may explicitly consider the possibility that they will not graduate, others may merely anticipate "bad luck," in which case the emotional consequences (e.g. anxiety) occur immediately, whether or not the material consequences ever occur. We observe anecdotal evidence for both.
} 


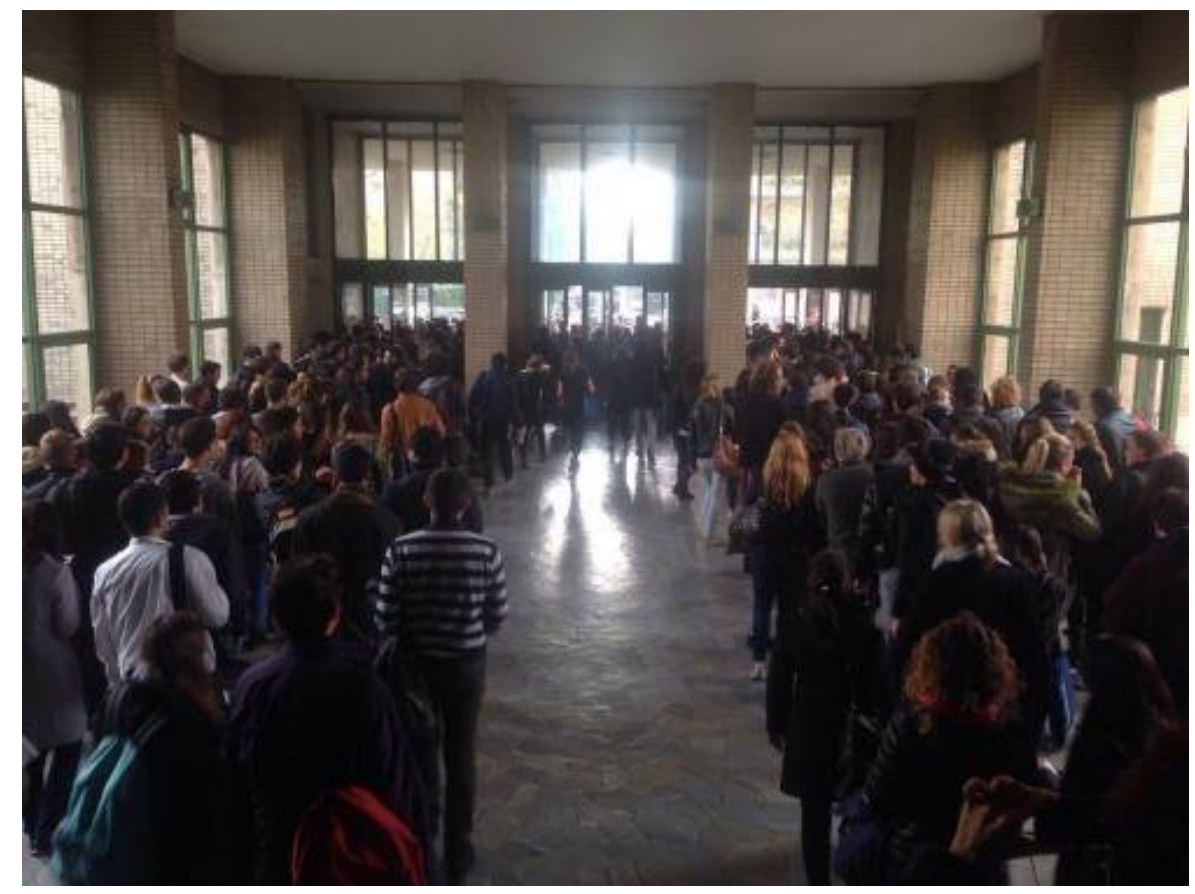

Figure 2: Students exiting the building during the fire drill.

whether students are willing to incur a qualitatively different, and arguably higher, cost to indulge in their aversion to walking between the lions.

Design An evacuation drill previously scheduled by the university was chosen to serve as a natural experiment in which the cost of avoiding walking between the lions was expected to increase substantially. During the drill, all persons inside the building are forced to walk immediately towards the only non-emergency exit to the building. With people avoiding walking between the lions while exiting, the increased flow created a bottle-neck at the lateral passageways, and lead to significant delays (about 60 seconds) in exiting the building for those who avoided walking between the lions, as can be seen in the photo presented in Figure $2 .^{12}$

\footnotetext{
${ }^{12}$ Many students evacuating eventually returned to their classrooms. For these students, a delay in exiting may not be as costly. On the other hand, it is arguably more pleasant
} 
In order to test whether a preference to conform plays a role in students' decision to avoid the middle passageway, we recruited 16 student confederates to walk between the lions with the goal of making it salient to students waiting that they would not stand out by walking between the lions, thereby reducing the cost of violating the taboo for someone with conformity motives. Moreover, if sufficiently many students followed, there was a potential for herd effect that could be self-sustaining. The confederates divided into four groups of four students each, and the groups exited the building by walking between the lines in a staggered manner, all exiting within a one minute period.

Results We divide the recording period into seven equally spaced time windows, each one lasting 30 seconds. The intervention occurred during the third time window. In Figure 3 we present the percentage of students walking between the lions in each time window. During the first and second time window students are already experiencing significant delays, yet, the percentage of people exiting the building (faculty and students) that walk between the lions does not increase marketedly above the baseline in the first two time windows. As can be seen in Figure 3, the intervention during the third time window has a notable effect that cascades into following periods, before eventually receding.

Discussion The results of Study 2 demonstrate that some students who behave in accordance with the superstitious rule will violate it if they observe other students near them doing so. This indicates that for these students, the aversion to walking between the lions is unrelated to a superstitious belief. Furthermore, because these students behaved in accordance with the rule before the intervention despite the cost of waiting, this suggests that

to wait outside the building with other students as it is away from the alarms, and the crowded line exiting the building. 


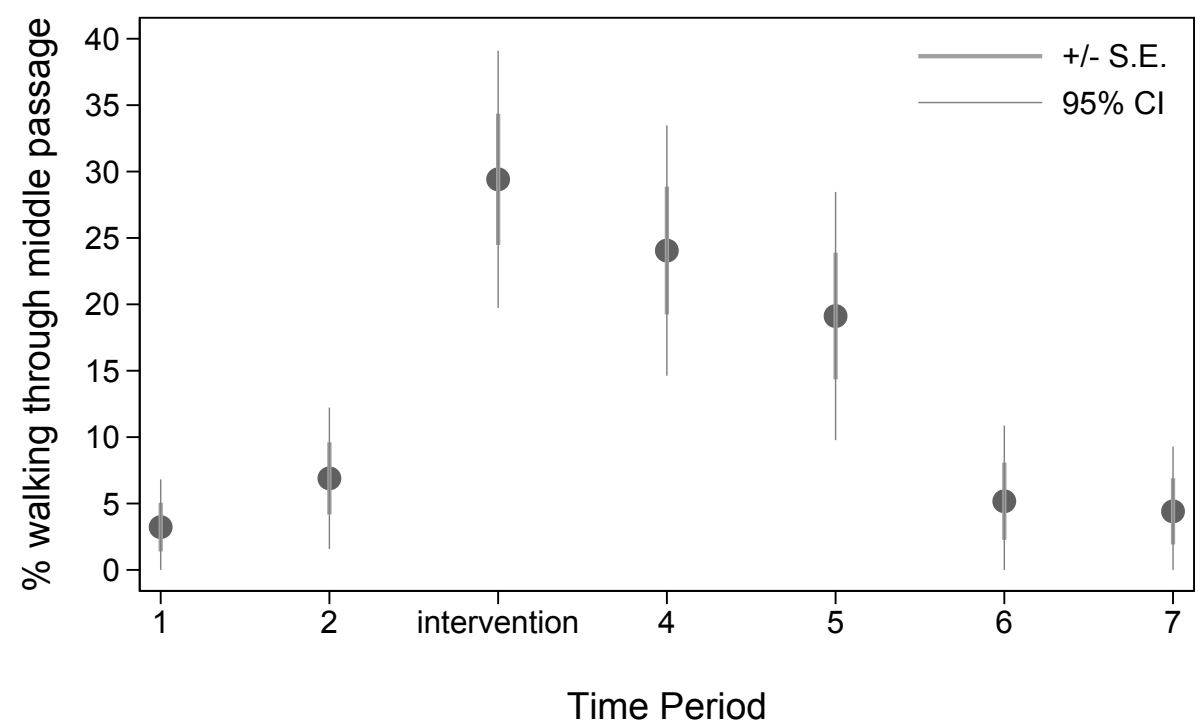

Figure 3: The percentage of students passing between the lions in each time interval. The standard errors are binomial with confidence intervals given by the normal approximation.

conformity, rather than herding, or habit explains their initial choice of the lateral passageway during the evacuation drill.

Importantly, because the majority of students continue to incur the nonnegligible cost of waiting despite the intervention, this leaves open the possibility that many students avoid walking between the lions because of a superstitious belief. Therefore there may exist a strongly held superstition among the a non-negligible subset of the student population.

\section{$4 \quad$ Walk-for-Pay - Study 3}

While the waiting cost in Study 2 is arguably higher than the detour cost in Study 1, the strength of the students' preference to adhere to their superstition is not clear. Our third study is designed to address this and investigate the prevalence of the aversion to walking between the lions in 
the student population, and to measure its strength in economic terms using a willingness-to-accept elicitation. Importantly, we conduct the study as a between-subjects treatment design by experimentally manipulating the scope for conformity motives. This feature of the design is important because while the confederate intervention in Study 2 demonstrates that a substantial fraction of students are willing to walk between the lions with the minimal cue of other students doing so, it is less clear whether this cue signals that they can avoid standing out, or if it simply signals there is a faster way to exit the building.

Design We measured the strength of students' aversion to walking between the lions by eliciting their minimum willingness-to-accept, in order to do so. The treatment, administered between subjects (block randomization), varied the degree to which subjects would "stand-out" if they were to walk between the lions

With the cooperation of a course instructor, the study was administered in the minutes just after students completed their final exam so that: (1) students would be more attentive and cooperative, (2) students would be seated to maximize privacy, (3) attendance would be maximized, (4) students would not be in a rush to attend another class, ${ }^{13}$ and (5) the superstition would potentially be more salient. The study was conducted in classrooms in the same building as the two lion statues in order to assure that there would be no fixed cost in walking from where their preferences were elicited to the building exit. We selected courses which included only students enrolled in their final semester at the university, so that their exposure to the superstition would be the greatest. A total of 183 students participated, with 93 students from the economics discipline, and 90 students from the law discipline. Because the demographics and educational background of law students place less emphasis on math and science than that of the economics students, we

\footnotetext{
${ }^{13}$ It is unlikely for a student to have commitments immediately after the exam as the exact ending time is typically not predictable.
} 
had reason to expect their willingness-to-accept to differ as well. ${ }^{14,15}$

Each participant received: (1) a sealed envelope with a random monetary offer, and (2) an attached sheet with a single-question eliciting their willingness-to-accept. There were two between-subjects experimental treatments which manipulated the scope for conformity motives: (1) the "Alone" treatment, in which it was emphasized that students who accepted the offer would walk between the lions alone, and (2) the "Group" treatment, in which it was emphasized that students who accepted the offer would walk between the lions with the other students who accepted. The translation of the question is presented below, where the text in bold corresponds to what varied randomly between subjects.

Please choose * one ${ }^{*}$ of the following three options by circling your chosen option. If you choose option B, please fill in the blank.

A. I will accept the payment written in my envelope, regardless of the amount, and walk, ["alone" / "together with the others that accept"], between the two lion statues as I exit the building.

B. I will accept the payment written in my envelope and walk, ["alone" / "together with the others that accept"], between the two lion statues as I exit the building, but I will do this only if the payment in my envelope is greater than or equal to Euros (and I will not accept if the payment is below this amount)

C. I will not accept the payment written in my envelope, regardless of the amount.

\footnotetext{
${ }^{14}$ In our subject pool, 33 percent of law students studied in a "Liceo Scientifico" (science-oriented high school) versus 58 percent of the economics students. In addition, economics students performed better in the mathematical section of the admission test with a 13.06/30 average score vs. 8.98/30 for the law students.

${ }^{15}$ For the economics students, their prior exposure to math and science may diminish the prevalence of superstitious belief, while their economics courses may lead to an increased tendency to choose more "rational" responses. For students choosing to study law, they may have a greater tendency to conform.
} 
The experimenter emphasized that the study was not a simulation, and that there were real monetary consequences to their decisions. In particular, the students were informed that (1) the offers involved a real payment in Euros, (2) their acceptance of an offer was binding, and (3) the only way they could avoid the possibility of accepting was to circling item $\mathrm{C}$, or to decline to participate by leaving the question blank. In order to increase the credibility and salience of the potentially large payments, the experimenter held up, for the students to see, the 3000 Euros in cash that was available, and then informed them that some of the envelopes contained offers in the hundreds of Euros. ${ }^{16}$ The students were informed that some of them would be paid for real by randomly drawing their response sheets after collecting them. ${ }^{17}$ More details on the procedure followed are presented in the appendix.

Results In Figure 4 we plot the percentage of students who choose to accept any offer (A) and the percentage of students who choose to reject any offer (C), by treatment (Alone vs. Group) and field of study (Law vs. Economics). As can be seen, nearly half of students will accept any offer in the alone treatment, whereas a minority 11 percent of students will reject any offer. The significant increase in the percentage of students accepting any offer in the group treatment is $14.7 p p(p<.05, S E=7.3 p p)$. The treatment does not appear to affect the students who reject any offer, with group treatment having just a marginally higher rate of rejections of $2.5 p p$ $(p=.58, S E=4.6 p p)$. The economics students appear to be more inclined to accept any offer, with a $12.5 p p$ higher rate of accepting any offer $(p<.10$, $S E=7.3 p p)$. The law students appear to be more inclined to reject any offer with a 11.2pp higher rate of rejecting any offer $(p<.05, S E=11.2 p p)$. This pattern of findings shows that conformity to the behavior of other students

\footnotetext{
${ }^{16}$ The amount in the envelope varied between 5 Euros and 150 Euros. We attempted to improve the credibility of the payment and the study in two ways: (i) we prominently displayed euro bills in the thousands that could be gained, (ii) we emphasized the seriousness of the study and the fact that student responses were to be taken as commitments.

${ }^{17}$ Ten students were selected to be paid in both the economics and law classes.
} 


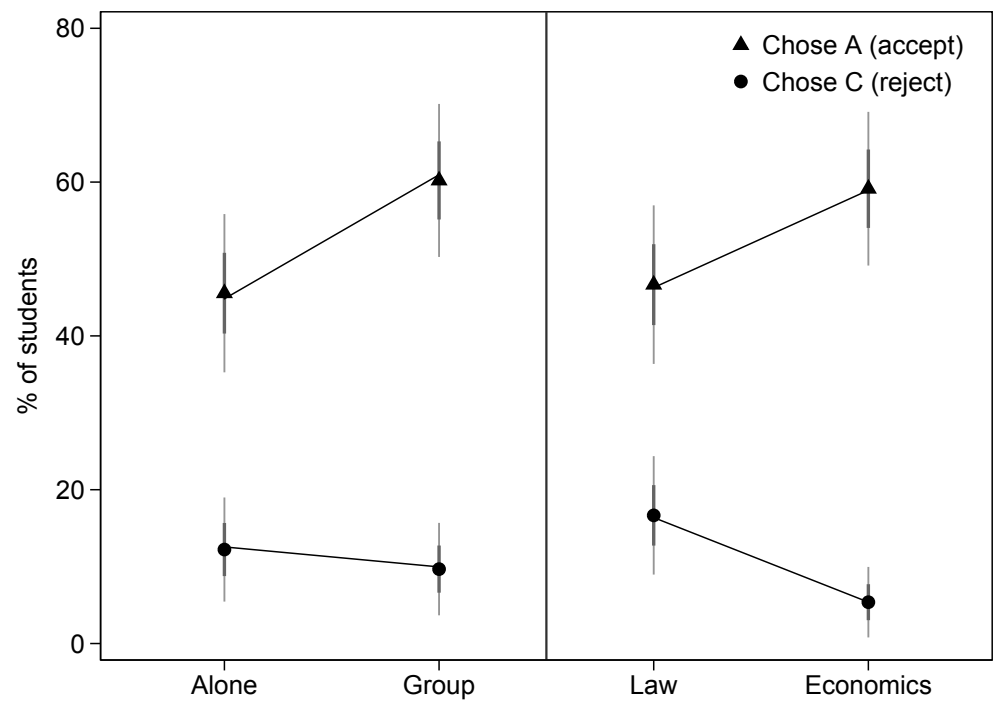

Figure 4: The percentage of students choosing (A), to accept any offer, or (C), to reject any offer, by treatment and classroom type. The standard errors are binomial with confidence intervals given by the normal approximation.

influences a significant fraction of students, and that the fraction of students for which the superstition is strong enough to reject any offer is small.

Next we include the students reporting a non-zero minimum willingnessto-accept (WTA) - i.e. choosing B - where we code WTAs that are greater than 1000 euros as 1000 euros because the instructions stated that the highest offer was in the hundreds. We also code the choice of $\mathrm{C}$ as 1000 euros, while the choice of $\mathrm{A}$ is coded as 0 euros. We find that that the median WTA in the alone treatment is 10 euros, while the median in the group treatment is 0 euros, which is a significant difference $(p<.05$, permutation test). The largest difference of WTAs appears at the 75th percentile where the group treatment has a WTA of 100 euros whereas the alone treatment has a WTA of 500 euros, this difference however is not significant. The cumulative distribution function of the WTA for each treatment is reported in Figure 5. As can be seen, the alone treatment first-order stochastically 


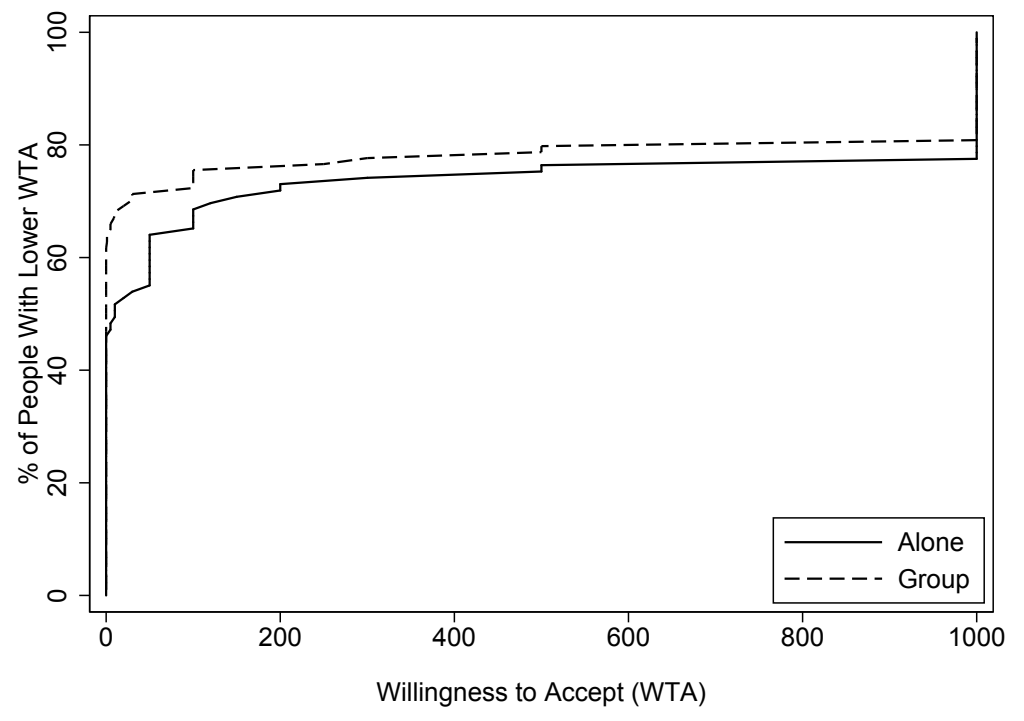

Figure 5: The cumulative distribution function of the willingness-to-accept (WTA) by treatment.

dominates the group treatment. The percentile WTA differences remain significant at the .05 level up to the 65 th percentile.

In Figure 6 we report the CDF of the WTAs by treatment, for each field of study. As can be seen, the CDF of the WTA accumulates mass at a faster rate among the economics students than among law students, regardless of treatment. Combined with the higher rate of choosing $A$, this fact leads to the law students' WTA first-order stochastically dominating that of economics students, regardless of the treatment. Further, the CDF indicates that group treatment has a stronger impact on the economics students' tendency to report a low WTA, although economics students tendency to report a low WTA regardless of treatment means that this early stochastic dominance by the alone treatment's CDF does not persist. For the law students on the other hand, because their CDF accumulates mass at a slower rate regardless of treatment, the stochastic dominance of the alone treatment persists throughout its support. 

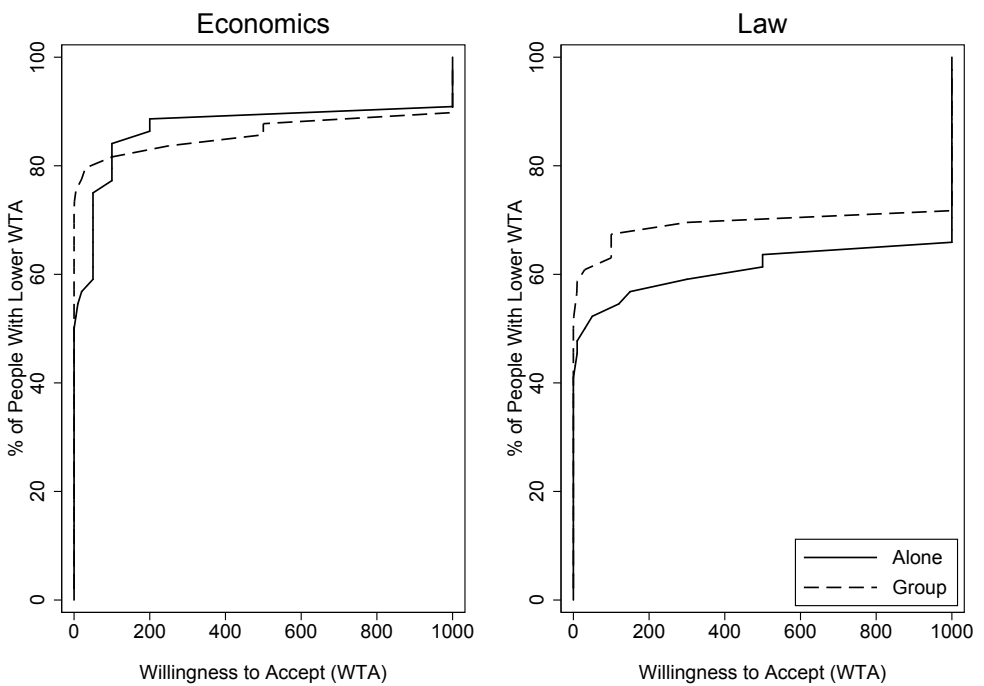

Figure 6: The cumulative distribution function of the willingness-to-accept (WTA) by treatment for each discipline of study.

\section{Discussion}

The stark pattern of near-universal adherence to a superstitious rule appears to be far less dramatic under closer examination. While we find what appears to be a dramatic exhibit of students avoiding walking between the lions when blocking of a lateral passageway (Study 1), and during an evacuation drill (Study 2), these patterns are belied by a modest intervention. During the evacuation drill students are willing to walk between the lions after seeing just a few members of their cohort walk between the lions. In the same way, when offered a payment to walking between the lions, nearly half of students revealed a willingness to accept any offer. While it is true that the 75 th percentile WTA is 250 euros, this amount is small relative to the potential negative consequences from violating the superstition (failing to graduate), indicating a vanishingly small probabilistic belief for a student who explicitly entertains one. 
On the other hand, a substantial minority of students are powerfully affected by the superstition in a way that does not appear to be explainable by conformity motives. Twenty percent of students require more than 1000 euros to pass between the lions (or will reject any offer), regardless of treatment. This rate is consistent with estimates of superstitious beliefs among students found in prior surveys (Albas and Albas 1989). ${ }^{18}$ Further, given that students are likely responding to their implicit beliefs - e.g. anticipated negative feelings or discomfort towards tempting fate - rather than their explicit beliefs - e.g. the probability of not graduating after walking between the lions - the fact that 35 percent of all subjects demand at least 50 euros indicates that this discomfort is widespread and non-negligible.

While the individual and social costs typically incurred from this behavior appear to be low, we have found that a substantial minority of students are willing to incur a relatively high individual cost. ${ }^{19}$ The existence of such a strong preference to avoid such an apparent triviality suggests that we should not underestimate the importance of superstition and other forms of magical thinking among a substantial segment of the population. More generally, policies that target false beliefs with the intention to change individual and group behavior may face substantial headwinds so long as those false beliefs are validated by the conforming behavior of the majority.

\footnotetext{
${ }^{18}$ Albas and Albas (1989) find that 20-33 percent of students engage in superstitious exam related behavior, albeit mostly in the form of bringing on good luck.

${ }^{19}$ Three anecdotes suggest that the actual WTAs may in some cases be higher than reported: (i) a student who reported a WTA of 120 euros expressed second thoughts when it came time to open the envelope, and then relief when it was revealed that the offer was only 65 euros, (ii) a student who reported a WTA of 1000 Euros was reminded that the offer was in the hundreds, the student affirmed that the reported amount was the minimum and did not request to modify the WTA, (iii) the students who accepted the offer expressed hesitation when it came to walk between the lions, even in the group treatment.
} 


\section{A Appendix: Study 3 Procedure}

The experiment was run over two days in three different classrooms. On the first day, two separate classrooms participated in the experiment, each containing approximately 50 test-taking students. These students, though, were of the same bachelor degree and the exam was the same in the two classrooms: the division was due to a space constraint only. On the second day, only one classroom participated in the experiment, but it had nearly 100 test-takers. The exam being taken in the first day was mathematics and in the second day, law. These exams fall under different departments and fields of studies within the university and therefore, it can be assumed there were no repeated students on the second day of experimentation.

The presiding exam proctors and responsible professors were approached no more than a few days prior to the exam as to minimize potential communication with the students. This also served to ensure that the experiment would not interfere with students' focus prior or during the exams.

Once the test-time was over and exams were collected, the responsible professor/proctor called for the attention of all students, and for them to remain in their spaced exam seating arrangement. The professor/proctor then read the following short paragraph given to them by the experimenters:

Can I have everyone's attention, you now have the opportunity to be paid for answering a single question, this will only take 5 minutes to hand out and collect your responses and you may make a considerable amount of money. If you need to leave, please leave quickly and quietly.

After reading the short paragraph and allowing students to leave the professor/proctor introduced one of the experimenters who announced:

We believe this is a great opportunity, that only requires five minutes of your time. Nevertheless, we understand that some of 
you might be in a rush. If this is the case, please raise your hand and leave the room in silence. Before we hand out the question, we want to remind you that exam rules still apply for this survey. Please do not talk to your neighbors or look at your neighbors sheets, and please don't let others look at your sheets. What we are handing out is real, it is a single question that involves real money and there is a considerable amount of money in some of these envelopes here so it is in your interest to respond to these questions carefully. We will hand you two things (1) an envelope and (2) a sheet of paper. You will hold on to the envelope until you leave, but you won't open it. You will quietly read the sheet, fill it out, fold it in half to keep it private, and return it to us. We will put your sheets of paper in this box, mix them up, and select 5(10) of them randomly, and if you are selected, you will be paid based on your decisions and the amount in your envelope.

After confirming that each student had a pen, they were reminded again of exam rules while the experimenters handed each of them one envelope with the hidden offer and one sheet of paper with instructions on one side and the response question on the other. Each item had a single matching code, which was unique to each student. The students were instructed not to open the envelope. Students were then asked to silently read page 1 and then turn it over to page 2 and respond. Students were further instructed that upon finishing they were to continue looking ahead per exam rules, and they were not to open the envelope. When students finished, the experimenters collected the sheets of paper leaving the envelopes with the students. Next the experimenter displayed the selected codes on the projector, and the remaining students were instructed to set their non-matching envelopes on the table, and to leave the room.

Next, selected students were pulled aside one by one to confirm their answers and check their unique identification code. After confirmation, they 
were individually told to open their envelopes.

Students in the alone treatment were individually walked downstairs to the entrance hall by an experimenter while another experimenter waited for them at the entrance. After passing in between the lion statues, the students in the alone treatment were asked to fill in a receipt form and were paid according to the amount reveled in their envelopes. The students were then told they were free to go. Enough time was given to each student to complete these tasks before the next student was walked downstairs to perform his/her task as to not allow students in the control group to be seen passing in between the lions by other students that were going to do the same.

Students in the treatment group repeated the same process as described above, except they were asked to pass together in between the statues, as indicated in their question.

\section{References}

Albas, D. and C. Albas (1989). Modern magic: The case of examinations. The Sociological Quarterly 30(4), 603-613.

Becker, G. M., M. H. Degroot, and J. Marschak (1964, January). Measuring utility by a single-response sequential method. Behavioral Science 9(3), $226-232$.

Bernheim, B. D. (1994). A theory of conformity. Journal of political Economy 102(5), 841-877.

Bernheim, B. D. and C. L. Exley (2015). Understanding conformity: An experimental investigation. Working Paper, December 10.

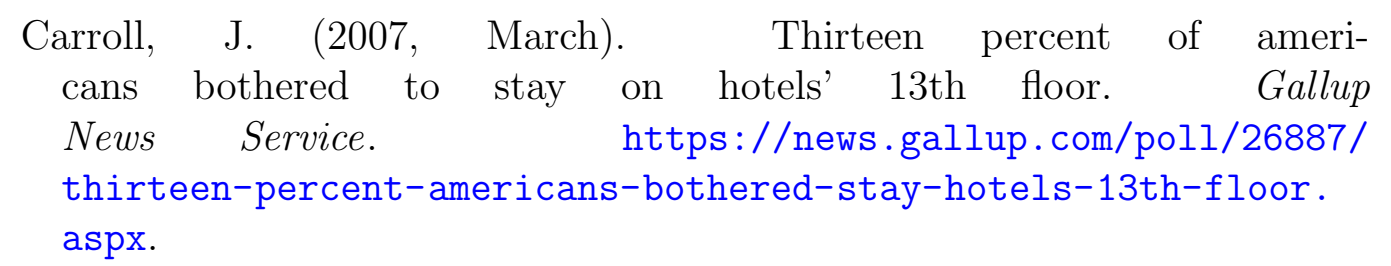


Goodkind, D. M. (1991). Creating new traditions in modern chinese populations: Aiming for birth in the year of the dragon. Population and Development Review, 663-686.

Hajikhameneh, A. and L. Iannaccone (2017). God games: An experimental study of uncertainty, superstition, and cooperation. Working Paper, December 10th.

Johnson, N. D. and J. V. Nye (2011, April). Does fortune favor dragons? Journal of Economic Behavior $\& 5$ Organization 78(12), 85-97.

Kramer, T. and L. Block (2008, April). Conscious and nonconscious components of superstitious beliefs in judgment and decision making. Journal of Consumer Research 34(6), 783-793.

Lindeman, M. and A. M. Svedholm (2012). What's in a term? paranormal, superstitious, magical and supernatural beliefs by any other name would mean the same. Review of General Psychology 16(3), 241-.

Perkins, B. (2002). Bottom line conjures up realty's fear of 13. Realty Times, http://realtytimes.com/todaysheadlines1/item/ 15685--20020913_13thfloor.

Pole, J., N. Berenson, D. Sass, D. Young, and T. Blass (1974). Walking under a ladder: A field experiment on superstitious behavior. Proceedings of the Division of Personality and Society Psychology 1(1), 10-12.

Pryor, C., A. Perfors, and P. D. Howe (2018). Even arbitrary norms influence moral decision-making. Nature Human Behaviour, 1.

Risen, J. L. (2016). Believing what we do not believe: Acquiescence to superstitious beliefs and other powerful intuitions. Psychological Review 123(2), $182-207$.

Vyse, S. A. (2013). Believing in Magic: The Psychology of SuperstitionUpdated Edition. Oxford University Press: New York, NY.

Wong, K.-F. and L. Yung (2005, July). Do dragons have better fate? Economic Inquiry 43(3), 689-697. 
Ya'akov, M. B., B. J. Ruffle, and Z. Shtudiner (2018). Costly superstitious beliefs: Experimental evidence. Journal of Economic Psychology 69, 3043.

Yip, P. S., J. Lee, and Y. Cheung (2002). The influence of the chinese zodiac on fertility in hong kong sar. Social Science $\mathcal{E}$ Medicine 55(10), 1803-1812. 